\title{
In ovo sexing of domestic chicken eggs by Raman spectroscopy
}

Roberta Galli ${ }^{1,}$, , Grit Preusse ${ }^{1}$, Ortrud Uckermann ${ }^{2}$, Thomas Bartels ${ }^{3}$, Maria-Elisabeth Krautwald-Junghanns ${ }^{3}$, Edmund Koch ${ }^{1}$, Gerald Steiner ${ }^{1,4}$

${ }^{1}$ TU Dresden, Faculty of Medicine, Anesthesiology and Intensive Care Medicine, Clinical Sensoring and Monitoring, Fetscherstrasse 74, D-01307 Dresden, Germany

2 TU Dresden, Faculty of Medicine, University Hospital Carl Gustav Carus, Neurosurgery, Fetscherstrasse 74, D-01307 Dresden, Germany

${ }^{3}$ University of Leipzig, Faculty of Veterinary Medicine, Clinic for Birds and Reptiles, An den Tierkliniken 17, D-04103 Leipzig, Germany

${ }^{4}$ Vilnius University, Faculty of Physics, Sauletekio av. 9 bl. 3, LT-10222 Vilnius, Lithuania

*Corresponding author: roberta.galli@tu-dresden.de

\section{Supporting Information}

\section{Supporting Figures}

Figure S-1. Thermal imaging.

Figure S-2. Example of Raman spectrum of embryonic chicken blood.

Table S-1. Raman bands of embryonic chicken blood.

Figure S-3. Analysis of characteristic band intensities depending from the classification results.

Figure S-4. Hatching experiment results. 


\section{Supporting Figures}
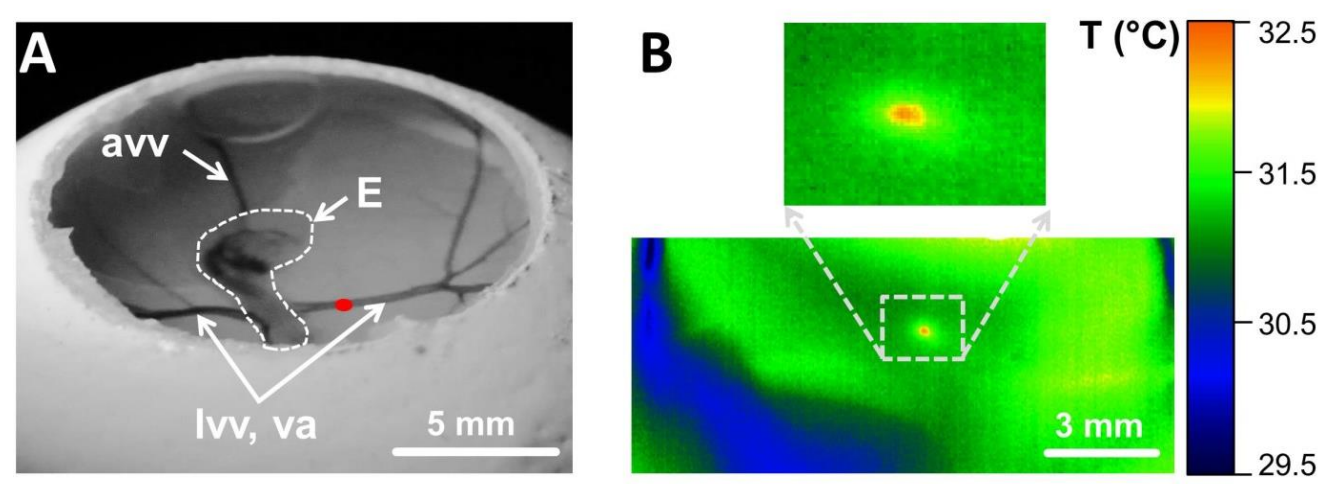

Figure S-1. Thermal imaging. A: Opened egg with exposed embryo and vitelline circulation (E: embryo, avv: anterior vitelline vein, Ivv, va: lateral vitelline veins and vitelline arteries). The red dot indicates a typical position of the Raman measurement. B: Thermal image of the egg surface during Raman measurement with detail showing the position of the laser focus, centered on lateral vitelline vessels as indicated by the red dot. The temperature of the surface was measured to be around $31.0^{\circ} \mathrm{C}$, as the eggs were opened and remained at ambient temperature for some minutes, while the maximum temperature measured in the laser focus was $32.5^{\circ} \mathrm{C}$. 


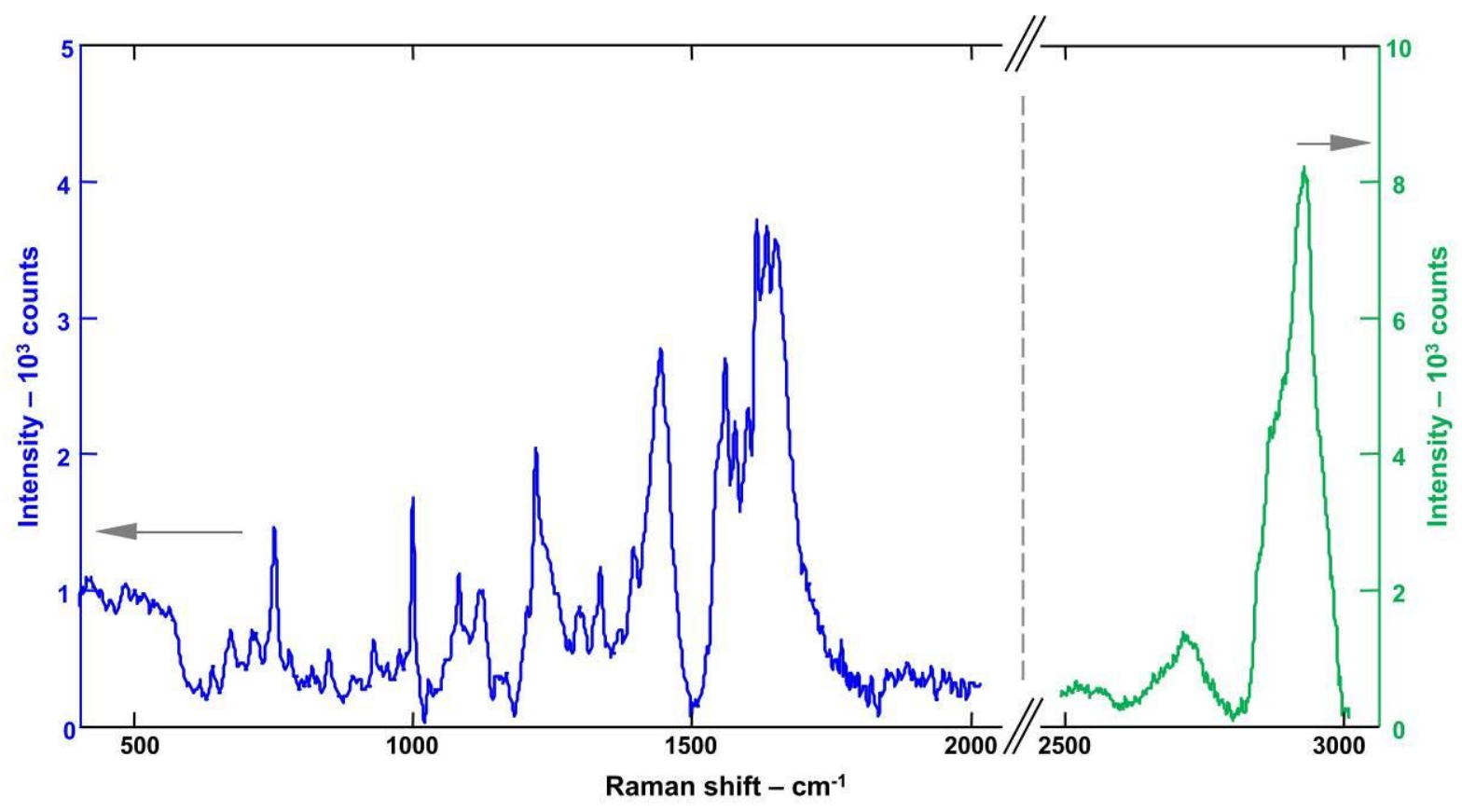

Figure S-2. Example of Raman spectrum of embryonic chicken blood. The spectrum was acquired in ovo at day 3.5 of incubation and was baseline corrected between $400 \mathrm{~cm}^{-1}$ and $3050 \mathrm{~cm}^{-1}$. Most of the bands are related to hemoglobin, for instance the band at 755 $\mathrm{cm}^{-1}$ and the bands between $1500 \mathrm{~cm}^{-1}$ and $1700 \mathrm{~cm}^{-1}$. The bands at $720 \mathrm{~cm}^{-1}$ and $785 \mathrm{~cm}^{-1}$ are assigned to vibration modes of nucleic acids. The bands at $1301 \mathrm{~cm}^{-1}$ and $1447 \mathrm{~cm}^{-1}$ are generated by deformations of $\mathrm{CH}_{\mathrm{x}}$ bonds, which can be originate from hemoglobin and other blood proteins (both in erythrocytes and plasma) and lipids. 


\begin{tabular}{|c|c|c|c|c|c|}
\hline $\begin{array}{l}\text { Raman } \\
\text { shift } \\
\left(\mathrm{cm}^{-1}\right)\end{array}$ & Band assignment & $\begin{array}{l}\text { Tissue } \\
\text { component }\end{array}$ & $\begin{array}{l}\text { Raman } \\
\text { shift } \\
\left(\mathrm{cm}^{-1}\right)\end{array}$ & Band assignment & $\begin{array}{l}\text { Tissue } \\
\text { component }\end{array}$ \\
\hline 568 & $v\left(\mathrm{Fe}-\mathrm{O}_{2}\right)$ & $\mathrm{HB}$ & 1125 & $v_{5}$ & $\mathrm{HB}$ \\
\hline 620 & $\delta(\mathrm{C}-\mathrm{C})$ twist phe. & Prot & 1160 & $v_{44}$ & $\mathrm{HB}$ \\
\hline 643 & $v(\mathrm{C}-\mathrm{S})$ & Prot. & 1172 & $v_{30}$ & $\mathrm{HB}$ \\
\hline 677 & $v_{7}$ Pyr. deform. & $\mathrm{HB}$ & 1208 & $v_{5}+v_{18} \quad \delta\left(C_{m} H\right)$ & $\mathrm{HB}$ \\
\hline 720 & Cytosine & NA & 1224 & $v_{13}$ or $v_{42} \delta\left(\mathrm{C}_{\mathrm{m}} \mathrm{H}\right)$ & $\mathrm{HB}$ \\
\hline 755 & $v_{15}$ Pyr. breathing & $\mathrm{HB}$ & 1248 & $v_{42} \delta\left(\mathrm{C}_{\mathrm{m}} \mathrm{H}\right)$ & $\mathrm{HB}$ \\
\hline 785 & $v(\mathrm{O}-\mathrm{P}-\mathrm{O}$, tymine $)$ & NA & 1301 & $v_{21} \quad \delta\left(\mathrm{C}_{m} \mathrm{H}\right)$ & $\mathrm{HB}$ \\
\hline 825 & $\gamma_{10}$ & $\mathrm{HB}$ & 1340 & $v_{41} \quad v($ pyr half-ring $)$ & $\mathrm{HB}$ \\
\hline 853 & $\gamma_{10}$ & $\mathrm{HB}$ & 1375 & $v_{4} \quad v($ pyr half-ring $)$ & $\mathrm{HB}$ \\
\hline 877 & Ribose & NA & 1400 & $v_{20} v($ pyr quater-ring $)$ & $\mathrm{HB}$ \\
\hline 900 & DNA skeletal & NA & 1447 & $\delta\left(\mathrm{CH}_{2}-\mathrm{CH} 3\right)$ & HB, Prot \\
\hline 933 & $v_{46}$ & $\mathrm{HB}$ & 1564 & $v_{19}$ & $\mathrm{HB}$ \\
\hline 956 & $v\left(\mathrm{CH}_{3}\right)$ & Prot & 1582 & $v_{37}$ & $\mathrm{HB}$ \\
\hline 980 & $\gamma\left(\mathrm{C}_{\mathrm{a}} \mathrm{H}=\right)$ & $\mathrm{HB}$ & 1604 & $v(\mathrm{C}=\mathrm{C})$ & $\mathrm{HB}$ \\
\hline 1003 & Phenylalanine & Prot & 1620 & $v(\mathrm{C}=\mathrm{C})$ & $\mathrm{HB}$ \\
\hline 1031 & $\delta\left(=\mathrm{C}_{\mathrm{b}} \mathrm{H}_{2}\right)_{4}$ & $\mathrm{HB}$ & 1639 & $v_{10}$ & $\mathrm{HB}$ \\
\hline 1047 & $v(\mathrm{O}=\mathrm{O})$ & $\mathrm{HB}$ & 1653 & Amide I & Prot. \\
\hline 1086 & $\delta\left(=\mathrm{C}_{\mathrm{b}} \mathrm{H}_{2}\right)_{4}$ & $\mathrm{HB}$ & 2933 & $v\left(\mathrm{CH}_{3}\right)$ & Prot. \\
\hline
\end{tabular}

Table S-1. Raman bands of embryonic chicken blood. HB: hemoglobin, NA: nucleic acids, Prot: proteins. Band assignment was made following references 23 to 26 . 


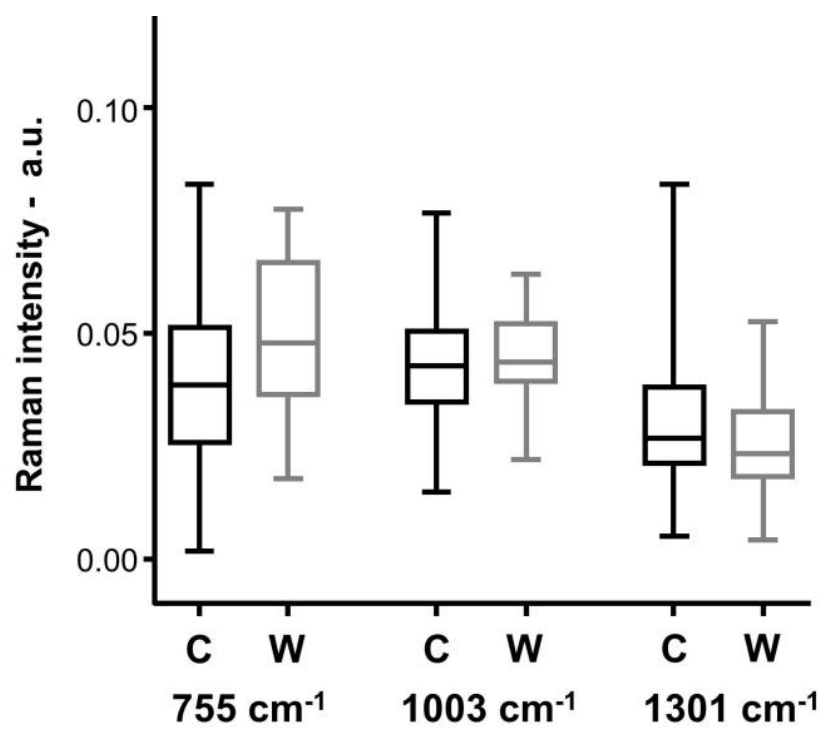

Figure S-3. Analysis of characteristic band intensities depending from the classification results. The bands at 755, 1003 and $1301 \mathrm{~cm}^{-1}$ were considered representative of blood, albumen and yolk respectively. Their intensity was analyzed separately for correctly $(\mathrm{C})$ and wrongly (W) classified spectra (line: median, box: $25^{\text {th }}$ to $75^{\text {th }}$ percentiles, whiskers: min-max).

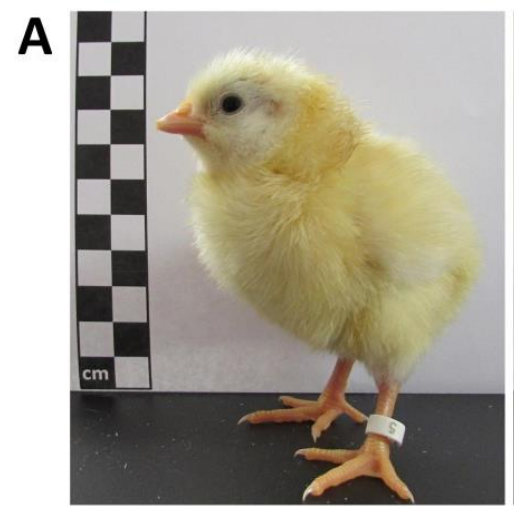

Raman

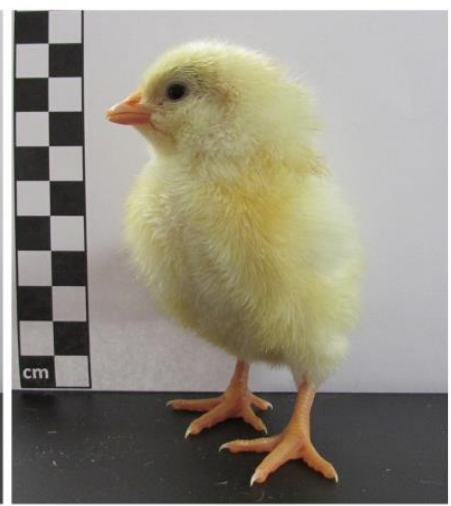

Control

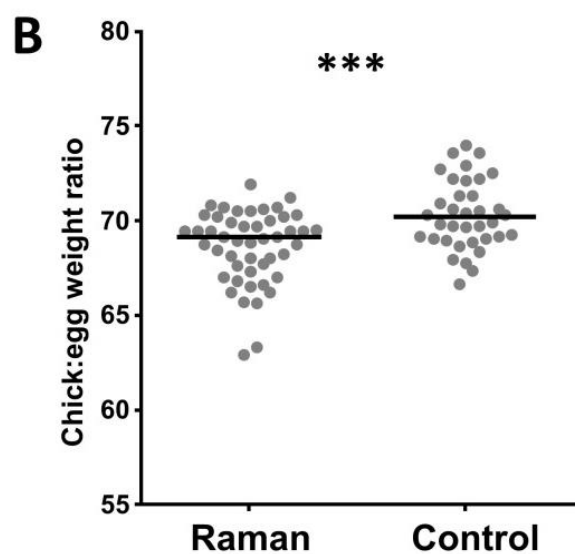

Figure S-4. Hatching experiment results. A: Picture of a representative one-day-old chick hatched from an egg that underwent Raman measurement (selected from the group of Figure 2B), compared to a control chick. B: Chick:egg weight ratio of test and control animals. Lines indicate mean values, t-test $p \leq 0.001$. 